REVIEW

\title{
Clinical associations of Dupuytren's disease
}

\author{
M G Hart, G Hooper
}

Postgrad Med J 2005;81:425-428. doi: 10.1136/pgmj.2004.027425

Dupuytren's disease (DD) is a common progressive fibrotic condition affecting the palmar and digital fascia. Although its management is undertaken by hand surgeons, it is commonly seen by other doctors as an incidental finding. In many cases it is believed to be associated with other medical conditions, although the evidence for such associations is not always clear. This review considers the evidence behind these associations and discusses the aetiology of DD. By doing so, it is hoped that this review will permit a better understanding of the relevance of $D D$ as a clinical sign.

See end of article for authors' affiliations

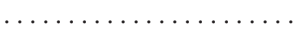

Correspondence to: Mr M G Hart, College of Medicine, Teviot Place, Edinburgh EH8 9AG, UK m.g.hart@sms.ed.ac.uk

Submitted 31 July 2004 Accepted

17 September 2004
B aron Guillaume Dupuytren first correctly identified the condition that bears his name as a chronic fibrotic contracture of the palmar fascia in $1833 .{ }^{1}$ Earlier descriptions can be found, proposing either a tendon contracture or a chronic inflammatory condition..$^{23}$ A similar affliction has been recorded in Norse folklore from the 12th century. It has been called the famed for its pipers in the 15th to 18th centuries, many of whom were unable to play in later life because of the contractures of their fingers. ${ }^{4}$

\section{CLINICAL FEATURES}

The overall incidence of Dupuytren's disease (DD) in the UK is around $4 \%,{ }^{5}$ rising to about $20 \%$ in those over 65 years. The condition may occur in several forms; one classification is shown in box 1, and typical cases are shown in figure 1. From this, it is clear that a contracture is not always necessary for a diagnosis, hence the term "Dupuytren's disease" is preferred.

Both hands are involved with equal frequency, and the condition is usually bilateral. It is usually more severe in one hand, but there is no relation to handedness. The ring finger is the most frequently involved, followed by the little finger, and then middle finger; the index finger and thumb are rarely involved. The diagnosis is usually obvious, although soft tissue tumours of the palm and digits may be confused with DD. Other conditions that cause joint contractures, such as osteoarthritis and the limited joint mobility seen in patients with long term diabetes, need to be distinguished.

\section{PATHOGENESIS}

Histologically, the cords of DD consist of a dense collagenous matrix containing fibroblasts, arranged along the longitudinal lines of stress. Nodules, which occur within the cords, contain myofibroblasts in bundles of collagen. ${ }^{7}$ Initially, "curse of the MacCrimmons", a Scottish clan there is a proliferative stage characterised by an increase in myofibroblasts. The subsequent involutional stage involves alignment of these cells along the longitudinal lines of tension. The microvessels within this tissue are considerably narrowed. ${ }^{8}$

The abnormal tissue contains increased glycosaminoglycans and collagen, with an increase in the ratio of type III to type I collagen. It has been suggested that DD is a result of local hypoxia and chronic ischaemia (fig 2). The xanthine oxidase pathway is believed to have a central role, ${ }^{9}$ while the palmar fat of those with DD has shown a lipid composition compatible with that of mild hypoxia. High levels of free radicals have been found, which can induce fibroblast proliferation in vitro. ${ }^{10}$

\section{ASSOCIATED CONDITIONS \\ Heredity}

A genetic susceptibility to the disease is the only generally agreed aetiological factor. DD is almost uniquely found in the white population, and only sporadically in those of African or Asian origin. ${ }^{11}{ }^{12}$ Even among European populations, there is a striking decrease in the prevalence of the condition between the north and south, while migrants from the north of Europe to the Mediterranean maintain their predilection. ${ }^{13}$ Northern Scotland, ${ }^{14}$ Iceland, ${ }^{15}$ Norway, ${ }^{16}$ and Australia $^{17}$ have the highest prevalence. The postulated Norse origins of the disease have been used to explain its distribution around the world, hence the term the "Viking disease". ${ }^{18}$

A familial form has been reported, suggesting an autosomal dominant pattern of inheritance with incomplete penetrance. ${ }^{19}$ This seems to be the exception rather than the rule, and other studies have been less conclusive. There is also an association with Peyronie's disease (idiopathic fibrosis of the corpora cavernosa), again with an autosomal dominant pattern of inheritance. ${ }^{20}$ A "Dupuytren's diathesis" has been noted, when DD develops to a severe degree in a young person with a strong family history.

\section{Alcohol}

An association of DD with alcohol is often quoted at the bedside. Indeed, it has been said that "many physicians, with a knowing wink when they spot that one of their patients has Dupuytren's contracture, mentally register that he is an alcoholic". ${ }^{21}$

However, before the 1950s there was only a single case in which the use of alcohol was considered an aetiological factor. ${ }^{22}$ A suspiciously high incidence of DD among the patients of a liver unit prompted further investigation in the 1950s. Chronic alcoholic patients with cirrhosis 


\section{Box 1 Grading of contractures ${ }^{6}$}

- Grade 1: a thickened nodule and band in the palmar aponeurosis, often with associated skin puckering

- Grade 2: as grade 1, with limitation of extension

- Grade 3: as grade 2, with a flexion contracture

of the liver had a prevalence of DD of $66 \%$, and alcoholic patients without cirrhosis $27 \% .^{23}$ Other studies confirmed this, ${ }^{24-26}$ and the belief that alcohol was an aetiological factor became established.

Liver disease in itself has also been suggested as an aetiological factor, after a high incidence of DD was noted in people with epilepsy receiving long term phenobarbital treatment, which also affects liver function. The question of

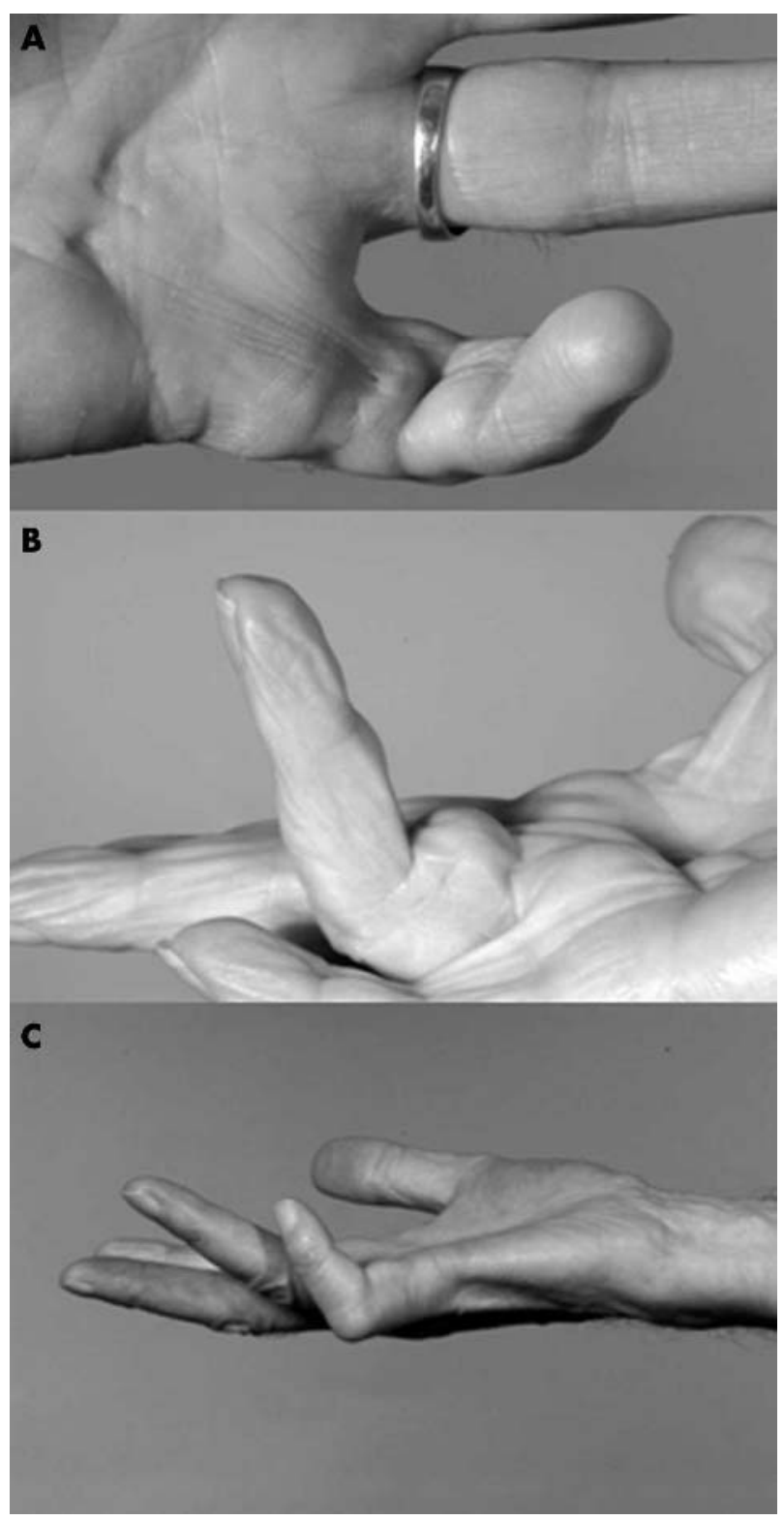

Figure 1 Forms of DD. (A) Skin puckering and band with flexion contracture of the little finger. (B) Moderate flexion contracture of the ring finger. (C) Limitation of extension of the ring finger and a flexion contracture of the little finger. whether DD is attributable to alcohol or liver disease seemed to be answered with the first prospective trial in the late 1980s. ${ }^{27}$ This study looked at 432 hospitalised patients, and used multivariate analysis to control for confounding variables. A similar prevalence was found between alcoholic patients with and without liver disease, leading to the conclusion that alcohol rather than liver disease was associated with DD. However, it was noted that in those with chronic cirrhotic liver disease, the presence of DD strongly suggested an alcoholic cause, with a $90 \%$ positive predictive value.

It seems that alcohol has a role in the aetiology of DD, although it was not clear if this relation is only true in alcoholic patients, or if those who drink more have a higher incidence of the disease. This hypothesis was examined in a group of Chelsea pensioners during the early 1990s, and it was found that DD was not more common in those who drank more alcohol.

In summary, it seems that alcoholic patients have an increased prevalence of DD. However, in the clinical situation it should be remembered that most of those with DD are not alcoholic patients. Some recent studies have supported the role for smoking in the aetiology of DD, and it has been speculated that heavy smoking common in alcoholic patients may explain the high prevalence of DD in this group. ${ }^{15}$

The mechanism whereby alcohol intake is associated with DD is unclear. Suggestions include effects on local circulation in the palm, damage to fatty tissue provoking a fibrotic response, and changes in prostaglandin production, but none of these mechanisms has been clearly established.

\section{Epilepsy}

A high prevalence among people with epilepsy was first noted in the 1940s in Denmark, with a prevalence of 50\% among male patients and $25 \%$ among female patients. ${ }^{28}$ Numerous studies have since investigated this connection, with incidences varying between $8 \%$ and $57 \% .^{29}$

There is good reason to believe that anticonvulsant drugs have a role, rather than a genetic association. There is a greater tendency for DD to be bilateral and symmetrical, ${ }^{29}$ and its incidence increases with the duration of epilepsy. ${ }^{30}$ Furthermore, DD occurs in all forms of epilepsy (including non-familial forms) with equal frequency, and there is no correlation with the severity of the epilepsy. ${ }^{28}$ There are no reports of anticonvulsant drugs increasing the incidence of DD in races other than white people. ${ }^{28}$ It seems that anticonvulsants alone cannot cause DD in populations that have a low risk of DD. People with epilepsy also have a higher incidence of knuckle pads (42\%) (fig 3) and plantar nodules (Ledderhose disease) in the foot $(30 \%),{ }^{30}$ suggesting a general propensity to chronic fibrotic conditions. These conditions may be a result from stimulation of tissue growth factors by anticonvulsants.

However, caution must be taken in interpreting the role of anticonvulsants in the aetiology of DD. Most studies have taken place in specialist epileptic centres, where the patients may not represent the general epileptic population. Furthermore, many studies have not been controlled for confounding variables, such as age.

\section{Trauma}

This was the original cause proposed by Dupuytren. ${ }^{1} \mathrm{He}$ described the hands of his coachman, supposedly affected because his steeds required him to use considerable effort with both hands for control. He also reported an affected wine merchant, who had noted a "cracking" noise heard when lifting one of his casks. Patients often believe it is heavy labour or trauma that has caused their condition.

The proposed links of DD with trauma inevitable led to claims for compensation from those injured at work. For this 


Vessel
narrowing Hypoxia $\square \begin{aligned} & \text { Activation } \\ & \text { of xanthine } \\ & \text { oxidase } \\ & \text { pathway }\end{aligned} \quad \begin{aligned} & \text { Release } \\ & \text { of free } \\ & \text { radicals }\end{aligned}$

Affect on $\square$ Abnormal Figure 2 Hypoxia theory.

fibroblasts tissue Microvascular narrowing is the initial event providing hypoxic conditions, stimulating fibroblasts, which then produce more free radicals that in turn cause further proliferation. reason, a review of the literature was undertaken in the early 1950s, and the hands of 1000 steelworkers, miners, and clerks were studied." ${ }^{31}$ No difference was found in the prevalence of DD between the different groups. Further studies have also concluded that the incidence or severity of DD is no more common among manual workers than in those whose main work does not entail manual labour. ${ }^{5}$

Despite this, numerous case reports have described DD occurring shortly after a penetrating traumatic injury, at the same site as the original wound. ${ }^{32}$ However, it was felt that immobility and swelling after injury were the provocative factors, and not the injury itself. While manual work and heavy labour do not seem to increase the risk of DD, it seems a specific injury may be able to trigger the onset of $\mathrm{DD}$, in those with a strong family history.

\section{Diabetes mellitus}

The association with diabetes mellitus (DM) is well recorded, with a reported prevalence of between $3 \%$ and $32 \%,{ }^{33}$ and an average of around $20 \%$. It is equally common in both type 1 and type 2 diabetes, although it occurs at a younger age in patients with type 1 diabetes. ${ }^{34} \mathrm{DD}$ occurring in diabetic patients is different from the condition in non-diabetic patients. There is a lower incidence of contractures, and fewer cases require surgery. ${ }^{33}$ Usually DD is more common in men, but in diabetic patients the sex ratio is equal. ${ }^{35}$

The exact relation of DD and diabetes has been the focus of much research. However, both conditions are common, and increase in prevalence with age. As a result, DD has been considered to be an early warning sign of diabetes or a late complication. ${ }^{36-38}$

There has been much debate about whether diabetes is an aetiological factor for DD, or whether the two conditions are inherited together. It is unlikely that DM has an important role in the aetiology of DD, as most of those with DM do not get DD. What then is the connection between DM and DD?

There is no relation between diabetic control and the severity of contractures, and DD has a generally milder form in diabetic patients. This suggests that diabetes may only be a triggering factor. It may be that microvascular changes in DM encourage local hypoxia, and this could elicit DD in those

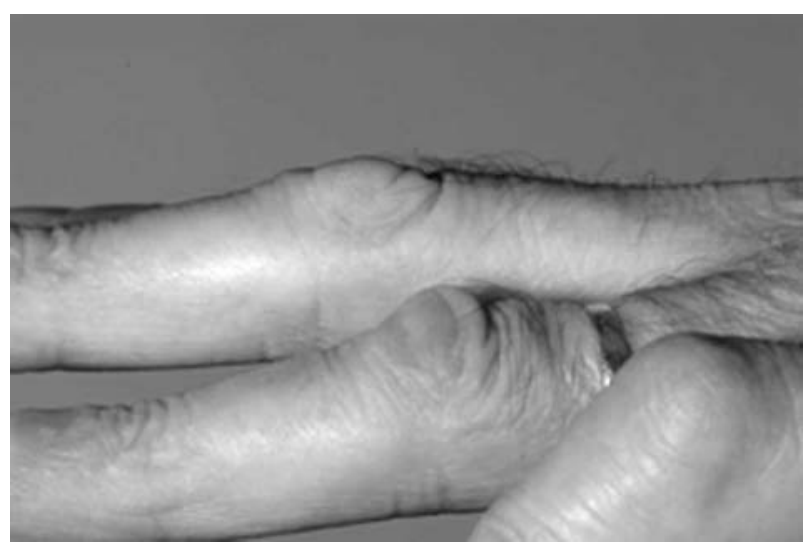

Figure 3 Knuckle pads. They may also occur along with plantar nodules as part of a Dupuytren's diathesis, where DD develops at a young age and to a severe degree, in those with a strong family history.

\section{Key references}

- Early P. Population studies in Dupuytren's contracture. J Bone Joint Surg 1962;44B:602-13.

- Elliot D. The early history of contracture of the palmar fascia. Part 1: The origin of the disease: the curse of the MacCrimmons: the hand of benediction: Cline's contracture. J Hand Surg 1988;13B:246-53.

- Gudmundsson KG, Arngrimsson R, Sigfusson N, et al. Epidemiology of Dupuytren's disease: clinical, serological, and social assessment. The Reykjavik study. J Clin Epidemiol 2000;53:291-6.

- Hueston JT. Dupuytren's contracture. Curr Orthop 1988;2:173-8.

- Arkkila PE, Kantola IM, Viikari JS. Dupuytren's disease: association with chronic diabetic complications. J Rheumatol 1997;24:153-9.

who would otherwise not have been affected. The microvascular changes that have been seen in DD are noted to be similar to those found in DM.

\section{Rheumatoid arthritis, gout, and human immunodeficiency virus}

Rheumatoid arthritis is the only condition so far noted to be associated with a lower incidence of $\mathrm{DD},{ }^{39}$ possibly because of anti-inflammatory drugs. ${ }^{7}$

Theoretically, patients with gout who are treated with allopurinol, which inhibits the xanthine oxidase pathway, should have a lower prevalence of DD, although this has not been established.

Patients with pulmonary tuberculosis were reported to have an incidence of DD of $50 \%$ in a study from the $1950 \mathrm{~s}^{40}$ There was a higher prevalence than usual in all age groups,

\section{Key points}

- Dupuytren's disease is a common clinical finding in those with other medical conditions, and those in otherwise good health.

- A genetic predilection is generally agreed upon, the condition being more common in those of northern European origin. It becomes more common with age.

- Trauma may trigger disease in those otherwise predisposed, although heavy labour is not associated with DD.

- The prevalence of DD is higher in alcoholic patients but the presence of DD in a person does not necessarily point to a high alcohol intake.

- There is an increased prevalence in those with diabetes mellitus and epilepsy.

- Insight is being gained into the pathological mechanisms of DD, which may clarify the roles of these associated conditions in the aetiology of DD. 
and an unusual number of cases among those under 30 . More recently, $36 \%$ of patients with HIV were noted to have DD, all of whom had advanced infection. ${ }^{41}$ It was suggested that the presence of DD may be a marker of deranged free radical metabolism, which may be an intermediary mechanism in the development of AIDS.

\section{CONCLUSIONS}

The significance of many of the conditions believed to be associated with DD is still not clear. A historical approach to the literature is of value, providing the reasoning behind many current beliefs. The fact remains that, over 170 years after Dupuytren's original description, the true cause of the condition still eludes us.

\section{SELF ASSESSMENT QUESTIONS (TRUE (T)/FALSE (F); ANSWERS AT END OF REFERENCES)}

1. In the proliferative phase of $\mathrm{DD}$, there is an increase in the number of fibrocytes within the tissue?

2. In the familial form of DD, all family members are severely affected?

3. DD is more common in those doing heavy and repeated manual labour?

4. The presence of DD is strongly suggestive of present or past alcoholism?

5. DD is more severe in people with diabetes who have poorer control of their diabetes?

\author{
Authors' affiliations \\ M G Hart, College of Medicine, Edinburgh, UK \\ G Hooper, St Johns Hospital, Livingston, UK \\ Funding: none. \\ Competing interests: none declared. \\ Ethical approval: none required.
}

\section{REFERENCES}

1 Dupuytren G. Permanent retraction of the fingers, produced by an affection of the palmar fascia'. Lancet 1834;ii:222-5.

2 Verheyden CN. The history of Dupuytren's contracture. Clin Plast Surg 1983;10:619-25

3 Moorhead JJ. Dupuytren's contracture: review of the disputed etiology1831-1956. N Y State J Med 1956;56:3686-9.

4 Elliot $D$. The early history of contracture of the palmar fascia. Part 1: The origin of the disease. The curse of the MacCrimmons: the hand of benedictionCline's contracture, J Hand Surg 1988;13B:246-53.

5 Early P. Population studies in Dupuytren's contracture. J Bone Joint Surg 1962;44B:602-13.

6 Su CK, Patek AJ Jr. Dupuytren's contracture. Its association with alcoholism and cirrhosis. Arch Intern Med 1970;126:278-81.

7 Murrell GA, Hueston JT. Aetiology of Dupuytren's contracture. Aust N Z J Surg 1990;60:247-52.

8 Murrell GA, Francis MJ, Howlett CR. Dupuytren's contracture. Fine structure in relation to aetiology. J Bone Joint Surg 1989;71B:367-73.

9 Murrell GA, Murrell TG, Pilowsky E. A hypothesis for the resolution of Dupuytren's contracture with allopurinol. Speculations Sci Technol 1987; 10:107-12.

10 Murrell GA. An insight into Dupuytren's contracture. Ann R Coll Surg Engl 1992;74:156-60.

11 Saboeiro AP, Porkorny JJ, Shehadi SI, et al. Racial distribution of Dupuytren's disease in Department of Veterans Affairs patients. Plast Reconstr Surg 2000;106:71-5.

12 Yost J, Winters T, Fett HC. Dupuytren's contracture; a statistical study. Am J Surg 1955;90:568-71.
13 Brouet JP. Etude de 1000 dossiers maladie de Dupuytren. In: Tubiana R, Hueston JT, eds. La Maladie de Dupuytren. Paris: Expansion Scientifique Francaise, 1962:98

14 Lennox IA, Murali SR, Porter R. A study of the repeatability of the diagnosis of Dupuytren's contracture and its prevalence in the Grampian region. J Hand Surg 1993; 18:258-61.

15 Gudmundsson KG, Arngrimsson R, Sigfusson N, et al. Epidemiology of Dupuytren's disease: clinical, serological, and social assessment. The Reykjavik study. J Clin Epidemiol 2000;53:291-6.

16 Mikkelsen OA, Hoyeraal HM, Sandvik L. Increased mortality in Dupuytren's disease. J Hand Surg 1999;24B:515-18.

17 Hueston JT. The incidence of Dupuytren's contracture. Med J Aust 1960;6:999-1002.

18 Hueston JT. Dupuytren's contracture. Curr Orthop 1988;2:173-8.

19 Ling RSM. The genetic factor in Dupuytren's disease. J Bone Joint Surg 1963;45B:709-18.

20 Carrieri MP, Serraino D, Palmiotto F, et al. A case-control study on risk factors for Peyronie's disease. J Clin Epidemiol 1998;51:511-15.

21 Carson J, Clarke C. Dupuytren's contracture in pensioners at the Royal Hospital Chelsea. J R Coll Physicians Lond 1993;27:25-7.

22 Skoog T. Dupuytren's contracture with special reference to its aetiology and improved surgical treatment. Its occurence in epileptics. Note on knuckle pads. Acta Chir Scand 1948;139(suppl 96):1-190.

23 Wolfe SJ, Summerskill WHJ, DC. Thickening and contraction of the palmar fascia (Dupuytren's contracture) associated with alcoholism and hepatic cirrhosis. NEJM 1956:255:559-63.

24 Summerskill DM, Davison CS, Dible JH, et al. Cirrhosis of the liver; a study of alcoholic and nonalcoholic patients in Boston and London. NEJM 1960;262:1-10.

25 Nazari B. Dupuytren's contracture associated with liver disease. J Mount Sinai Hosp N Y 1966:33:69-72

26 Pojer J, Radivojevic M, Williams TF. Dupuytren's disease. Its association with abnormal liver function in alcoholism and epilepsy. Arch Intern Med 1972; 129:561-6

27 Attali P, Ink O, Pelletier G, et al. Dupuytren's contracture, alcohol consumption, and chronic liver disease. Arch Intern Med 1987;147:1065-7.

28 Lund M. Dupuytren's contracture and epilepsy. Acta Psychiatry Neurol $1941 ; 16: 465-92$

29 Arafa M, Noble J, Royle SG, et al. Dupuytren's and epilepsy revisited. J Hand Surg 1992;17:221-4

30 Critchley EM, Vakil SD, Hayward HW, et al. Dupuytren's disease in epilepsy: result of prolonged administration of anticonvulsants. J Neurol Neurosurg Psychiatry 1976;39:498-503.

31 Herzog EG. The aetiology of Dupuytren's contracture. Lancet 1951;i:1305-10.

32 Hueston JT. Dupuytren's Contracture and specific injury. Med J Aust $1968 ; 1: 1084-5$.

33 Noble J, Heathcote JG, Cohen H. Diabetes mellitus in the aetiology of Dupuytren's disease. J Bone Joint Surg 1984;66:322-5.

34 Arkkila PE, Kantola IM, Viikari JS. Dupuytren's disease: association with chronic diabetic complications. J Rheumatol 1997;24:153-9.

35 Arkkila PE, Kantola IM, Viikari JS, et al. Dupuytren's disease in type 1 diabetic patients: a five-year prospective study. Clin Exp Rheumatol 1996;14:59-65.

36 Heathcote JG, Cohen H, Noble J. Dupuytren's disease and diabetes mellitus. Lancet $1981 ; \mathrm{i}: 1420$

37 Larkin JG, Frier BM. Limited joint mobility and Dupuytren's contracture in diabetic, hypertensive and normal populations. BMJ 1986;292:1494.

38 Lawson PM, Maneschi F, Kohner EM. The relationship of hand abnormalities to diabetes and diabetic retinopathy. Diabetes Care 1983;6:140-3.

39 Arafa M, Steingold RF, Noble J. The incidence of Dupuytren's disease in patients with rheumatoid arthritis. J Hand Surg 1984;9:165-6.

40 Gordon S. Dupuytren's contracture; the significance of various factors in its aetiology. Ann Surg 1954;140:683-6.

41 Bower M, Nelson M, Gazzard BG. Dupuytren's contractures in patients infected with HIV. BMJ 1990;300:164-5.

\section{ANSWERS}

1. (F) There is an increase in the number of myofibroblasts, not mature fibrocytes; 2 . (F) Only selected family members are affected, to varying degrees; 3. (F) It may however arise after a specific injury to the palm; 4 . (F) Most of those with DD are not alcoholic patients. Certain groups with severe alcoholism and liver disease do have a higher incidence; 5. (F) In contrast, DD usually follows a more benign course in diabetic patients, with fewer cases presenting for surgery. 